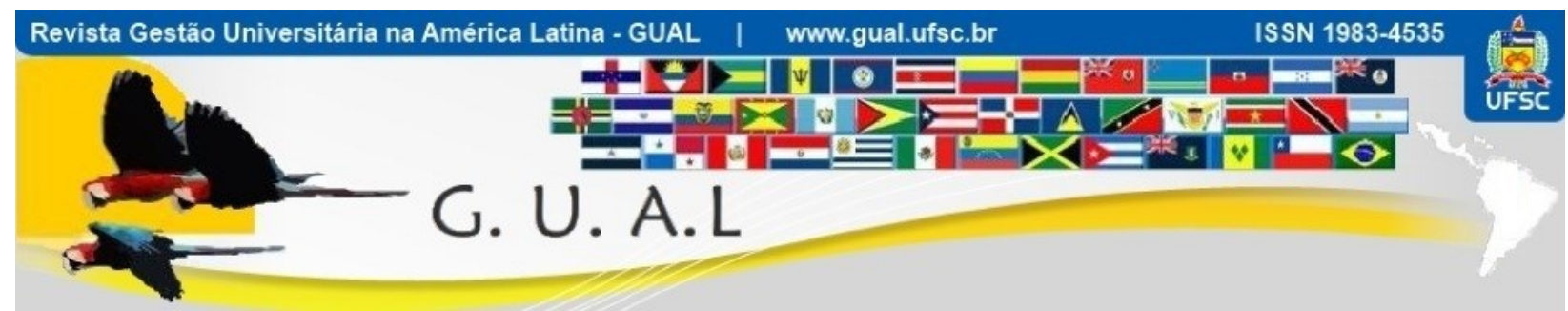

DOI: https://doi.org/10.5007/1983-4535.2021.e79844

\title{
FATORES EXPLICATIVOS DO NÍVEL DE UTILIZAÇÃO DAS ESTRATÉGIAS METACOGNITIVAS DE APRENDIZAGEM AUTORREGULADA DOS ESTUDANTES DE CONTABILIDADE
}

\section{EXPLANATORY FACTORS OF THE LEVEL OF USE OF METACOGNITIVE STRATEGIES OF SELF-REGULATED LEARNING OF ACCOUNTING STUDENTS}

Thiago Bruno de Jesus Silva, Doutor https://orcid.org/0000-0002-1128-6601 thiagobsilva@ufgd.edu.br Universidade Federal da Grande Dourados | Departamento de Ciências Contábeis Dourados | Mato Grosso do Sul | Brasil

Gerson João Valeretto, Doutor https://orcid.org/0000-0002-2012-0072 gerson valeretto@hotmail.com Universidade Federal da Grande Dourados | Departamento de Ciências Contábeis Dourados | Mato Grosso do Sul | Brasil

Marília Paranaíba Ferreira, Mestre https://orcid.org/0000-0003-4290-8589 mariliaferreira82@hotmail.com Universidade Federal de Santa Catarina | Programa de Pós-Graduação em Contabilidade Florianópolis | Santa Catarina | Brasil

Cleston Alexandre dos Santos, Doutor https://orcid.org/0000-0001-7014-6644 cleston.alexandre@ufms.br

Universidade Federal do Mato Grosso do Sul | Programa de Pós-Graduação em Ciências Contábeis Campo Grande | Mato Grosso do Sul | Brasil

Cristian Baú Dal Magro, Doutor https://orcid.org/0000-0002-7609-5806 crisbau@unochapeco.edu.br Universidade da Região de Chapecó | Programa de Pós-Graduação em Ciências Contábeis e Administração Recebido em 03/março/2021 Chapecó | Santa Catarina | Brasil Aprovado em 07/julho/2021

Publicado em $01 /$ setembro/2021

Sistema de Avaliação: Double Blind Review

Esta obra está sob uma Licença Creative Commons Atribuição-Uso. 


\title{
FATORES EXPLICATIVOS DO NÍVEL DE UTILIZAÇÃO DAS ESTRATÉGIAS METACOGNITIVAS DE APRENDIZAGEM AUTORREGULADA DOS ESTUDANTES DE CONTABILIDADE \\ DOI: https://doi.org/10.5007/1983-4535.2021.e79844
}

\section{RESUMO}

Este estudo objetiva identificar os fatores que explicam o nível de utilização das estratégias metacognitivas de aprendizagem autorregulada dos estudantes de contabilidade. Os dados foram coletados por meio de questionários aplicados aos discentes do curso presencial de Ciências Contábeis de uma instituição federal do estado do Mato Grosso do Sul/Brasil e, no total, 107 questionários, fundamentados na metodologia Self-Regulated Learning (SRL), fizeram parte da amostra. As análises consideraram as 14 estratégias metacognitivas de aprendizagem autorregulada definidas por Zimmerman e Martinez-Pons (1986) e foram feitas mediante as técnicas de estatística descritiva, análise fatorial e regressão linear múltipla. Como resultado, a nota de desempenho acadêmico e o tempo de estudo apresentaram significância com o nível de utilização das estratégias da dimensão Estabelecimento de objetivos e Execução; o tempo de estudo influencia o nível de utilização das estratégias da dimensão Autoavaliação, Organização e Estrutura Ambiental; e a síndrome do impostor e a idade apresentaram relação com o nível de utilização das estratégias da dimensão Autoconsequência e Repetição e memória. Como implicações, as descobertas empíricas podem subsidiar professores, acadêmicos, pesquisadores e instituições educacionais a compreenderem como estes estudantes estruturam suas ações em sala de aula, sobretudo porque muitas dessas ações podem estar ancoradas nas próprias atitudes docentes. Logo, conclui-se que o professor também pode auxiliar o aluno a encontrar o próprio caminho de regulação das atividades que realiza, a valorizar as estratégias que ele utiliza e a descobrir novas trajetórias.

Palavras-chave: Estratégias Metacognitivas. Estratégias de Aprendizagem. Aprendizagem Autorregulada. Síndrome do Impostor. Educação Contábil.

\begin{abstract}
This study aims to identify the factors that explain the level of use of metacognitive strategies for self-regulated learning of accounting students. The data were collected through questionnaires applied to students of presential accounting course at a federal institution in the state of Mato Grosso do Sul/Brazil and, in total, 107 questionnaires, based on the SelfRegulated Learning (SRL) methodology and Clance Impostor Phenomenon Scale (CIPS), were part of the sample. The analyzes considered the 14 metacognitive strategies of selfregulated learning defined by Zimmerman and Martinez-Pons (1986) and were made using the techniques of descriptive statistics, factor analysis and multiple linear regression. As a result, the academic performance score and the time of study were significant with the level of use of the strategies of the Objective-setting and Execution dimension; the study time influences the level of use of the strategies of the Self-Assessment, Organization and Environmental Structure dimension; and the imposter syndrome and age were related to the level of use of the strategies of the Self-consequence and Repetition and memory dimension. As implications, the empirical findings can support professors, academics, researchers and educational institutions to understand how these students structure their actions in the classroom, especially because many of these actions may be anchored in the teaching attitudes themselves. Therefore, it is concluded that the professors can also help the student to find his own way of regulating the activities he performs, to value the strategies he uses and to discover new trajectories.
\end{abstract}

Keywords: Metacognitive Strategies. Learning Strategies. Self-Regulated Learning. Impostor Syndrome. Accounting Education. 


\section{FATORES EXPLICATIVOS DO NÍVEL DE UTILIZAÇÃO DAS ESTRATÉGIAS METACOGNITIVAS DE \\ APRENDIZAGEM AUTORREGULADA DOS ESTUDANTES DE CONTABILIDADE \\ DOI: https://doi.org/10.5007/1983-4535.2021.e79844}

\section{INTRODUÇÃO}

A busca constante pelo aprendizado permite pensamentos mais críticos, por isso os profissionais de contabilidade devem ser eternos aprendizes, além de pensadores participativos (KNOWLES, 1984; SCHLEIFER; DULL, 2009; AAA, 2012; SILVA; BIAVATTI, 2018). Nesse sentido, o desenvolvimento de habilidades metacognitivas de aprendizagem autorregulada possibilita melhor adaptação às mudanças acadêmicas e profissionais, bem como o conhecimento de novos conteúdos para alcançar o sucesso acadêmico e profissional (SMITH, 2001; BECKER, 2013).

Para Dweck (2002), os indivíduos autorregulados têm consciência dos seus pontos fortes e fracos, conseguem agrupar estratégias que contornam características insuficientes para executar determinadas tarefas acadêmicas e estimulam habilidades que ajudam a superar desafios. McCann (2000) conceitua o uso de estratégias metacognitivas de aprendizagem autorregulada de acordo com a reação dos estudantes, ou seja, se eles estabelecem contingências de recompensa, se reforçam sua autoeficácia e expectativa de sucesso ou se eles lembram das consequências positivas (negativas) do sucesso (fracasso).

Entretanto, muitos estudantes lutam contra a síndrome do impostor (BOWMAN; PALMER, 2017). Ashrafifard e Mafakheri (2017) reconhecem que as habilidades metacognitivas podem ter relação com o comportamento impostor, visto que a síndrome do impostor ocorre quando os indivíduos não acreditam que o seu sucesso possa ser atribuído à sua própria capacidade (ROSKOWSKI, 2010). Pintrich (2000) explica que a característica pessoal guia e/ou limita o processo construtivo ativo, por meio do qual o aluno estabelece metas para o seu aprendizado e, em seguida, tenta monitorar, regular e controlar sua cognição, motivação e comportamento na direção dos objetivos.

Ao abordar a característica pessoal, estudos evidenciam a existência de diferenças significativas entre fatores que influenciam o nível de utilização das estratégias metacognitivas de aprendizagem autorregulada, como idade, gênero, estágio no curso, tempo de estudo e desempenho acadêmico (ROSÁRIO, 2001; BEMBENUTTY, 2007; LOMBAERTS; ENGELS; VAN BRAAK, 2009; SCHLEIFER; DULL, 2009; PARRA et al., 2014; LIMA FILHO; LIMA; BRUNI, 2015; PAVESI; ALLIPRANDINI, 2015; SILVA et al., 2016; SILVA; BIAVATTI, 2018; SILVA et al., 2020).

De modo geral, os resultados indicam que não há clareza suficiente quanto a possível relação entre esses fatores e o controle exercido pelos estudantes sobre o seu próprio processo 


\section{FATORES EXPLICATIVOS DO NÍVEL DE UTILIZAÇÃO DAS ESTRATÉGIAS METACOGNITIVAS DE APRENDIZAGEM AUTORREGULADA DOS ESTUDANTES DE CONTABILIDADE \\ DOI: https://doi.org/10.5007/1983-4535.2021.e79844}

de aprendizagem (STUDENSKA, 2011), o que motiva a presente pesquisa. Além disso, no que se refere ao nível de uso das estratégias metacognitivas de aprendizagem autorregulada e a síndrome do impostor, não é encontrado estudo empírico anterior que comprove tal relação. Neste quesito, segundo Bowman e Palmer (2017), tem-se a necessidade de pesquisas que buscam entender as várias formas pelas quais este fenômeno se manifesta, sobretudo porque ele pode dificultar o aprendizado dos estudantes.

Posto isto, identificar na literatura preditores que expliquem o nível de utilização das estratégias metacognitivas de aprendizagem autorregulada dos estudantes de contabilidade por meio da idade, gênero, estágio no curso, tempo de estudo, nota de desempenho acadêmico, bem como da síndrome do impostor, se torna um problema de pesquisa, ao que tudo indica, ainda não explorado. Desta forma, com base neste contexto e a partir desta plataforma teórica, desenvolve-se o seguinte problema de pesquisa: Quais fatores explicam o nível de utilização das estratégias metacognitivas de aprendizagem autorregulada dos estudantes de contabilidade? Assim, o objetivo é identificar quais fatores explicam o nível de utilização das estratégias metacognitivas de aprendizagem autorregulada dos estudantes de contabilidade de uma instituição federal do estado do Mato Grosso do Sul/Brasil.

A relevância e contribuição teórica deste estudo versam em obter conhecimento sobre os preditores que explicam o nível de utilização das estratégicas metacognitivas de aprendizagem autorregulada dos estudantes de contabilidade. Esta pesquisa também se justifica pela importância de se entender o fenômeno impostor, que está relacionado às habilidades metacognitivas, uma vez que as descobertas empíricas podem ajudar professores, estudantes, pesquisadores, instituições de ensino e programas de pós-graduação a compreenderem como os estudantes estruturam suas ações em sala de aula, especialmente porque muitas dessas ações podem estar ancoradas nas próprias atitudes docentes. Assim, acredita-se que o professor também pode auxiliar o aluno a encontrar o próprio caminho de regulação das atividades que realiza, a valorizar as estratégias que ele utiliza e a descobrir novas trajetórias.

Como contribuição prática, os resultados podem facilitar o aperfeiçoamento das práticas de ensino de contabilidade, por oferecer possíveis explicações para o nível de utilização das estratégias de aprendizagem e por estimular o conhecimento sobre diferentes habilidades metacognitivas entre os estudantes, as quais comumente são influenciadas pelos próprios docentes (PARRA et al., 2014). Essa contribuição se torna imprescindível à luz do 
reconhecimento de que os estudantes, futuros profissionais, de contabilidade necessitam desenvolver habilidades de pensamento crítico e de aprendizagem continuada para aconselhar tomada de decisões de qualidade, objetivo também instigado pelo Instituto Americano de Contadores (American Institute of Certified Public Accountants - AICPA, 1999). A esse respeito, nota-se um número ainda incipiente de pesquisas empíricas (LIMA FILHO; LIMA; BRUNI, 2015).

Em relação ao aspecto social, este estudo pode contribuir com reflexões sobre o ensino-aprendizagem elaborado com a intenção de armazenar conhecimentos, aspecto presente no campo da Ciências Contábeis, bem como levantar questões sobre os fatores que possuem relação com as habilidades dos estudantes, visando torná-los efetivos tomadores de decisões. A construção educacional da aprendizagem autorregulada é alinhada com a aprendizagem ao longo da vida e com o conjunto de habilidades que prepara os profissionais para o mundo contemporâneo, e, conforme Becker (2011), a escassez observada de estudos relacionados às competências de aprendizagem para efeito de aprendizagem ao longo da vida no curso de Ciências Contábeis justifica a realização de novos estudos.

\section{REFERENCIAL TEÓRICO}

\subsection{ESTRATÉGIAS METACOGNITIVAS DE APRENDIZAGEM AUTORREGULADA E A SÍNDROME DO IMPOSTOR}

Cihanoglu (2012) explica que dada a velocidade em que ocorre mudanças e inovações no conhecimento, é necessário qualificar indivíduos, socialmente e mentalmente, em aprendizes ativos, que estejam cientes de sua própria cognição, do seu pensamento crítico e de consciência metacognitiva. Flavell (1987) pondera que o uso da cognição e da metacognição possibilita o armazenamento de elementos da informação, por isso a nova informação é incorporada às informações que já estavam armazenadas e atua na consciência do indivíduo por meio da forma em que o conhecimento é adquirido, sendo que o próprio indivíduo gerencia o processo, utilizando estratégias metacognitivas para a aprendizagem e resolução de problemas cotidianos.

Para Schleifer e Dull (2009), uma base para aprendizagem ao longo da vida em contabilidade permite ao estudante aprender a aprender, manter competências e conhecimentos, além de orientação profissional, fatores necessários para atender as organizações. Papazoglou (2010) conclui que a metacognição fornece meios para interligar 


\section{FATORES EXPLICATIVOS DO NÍVEL DE UTILIZAÇÃO DAS ESTRATÉGIAS METACOGNITIVAS DE \\ APRENDIZAGEM AUTORREGULADA DOS ESTUDANTES DE CONTABILIDADE \\ DOI: https://doi.org/10.5007/1983-4535.2021.e79844}

pensamentos, crenças e histórias pessoais e profissionais que influenciam, com suas experiências, a aprendizagem. Este é um processo deliberado para provocar alterações, visto que, por meio da metacognição, o aluno de contabilidade automonitoriza, modifica e transforma o que já é conhecido.

Segundo Zimmerman e Martinez-Pons (1986), a metodologia Self-Regulated Learning (SRL), oriunda da Teoria da Metacognição, apresenta 14 possíveis estratégias metacognitivas de aprendizagem autorregulada. Para os autores, o uso dessas estratégias confere ao aluno uma valiosa ferramenta, pois sua utilização está altamente correlacionada com os índices de sucesso acadêmico e com a opinião dos docentes acerca do seu grau de autorregulação em sala de aula. As estratégias são: 1) Autoavaliação; 2) Organização e transformação; 3) Estabelecimento de objetivos e planejamento; 4) Procura de informação; 5) Apontamentos; 6) Estrutura ambiental; 7) Autoconsequência; 8) Repetição e memorização; 9) Ajuda de professores; 10) Ajuda de pares próximos; 11) Ajuda de especialistas; 12) Revisão das anotações; 13) Revisão de testes e 14) Revisão da bibliografia.

O tempo de estudo pode ser uma ferramenta interessante para o treino regulatório dos estudantes (CHAMBERS, 1992). Os resultados de Ericsson e Charnes (1994), por exemplo, indicaram que os discentes mais proficientes no uso das estratégias gastam ao longo do percurso acadêmico, por vezes, mais de 10.000 horas em trabalho individual, o que chamaram de "prática deliberada".

Zimmerman (2000) explica que as estratégias seguem uma perspectiva sociocognitiva, ao analisar os processos psicológicos implicados nas diversas fases da autorregulação: fase de antecipação e preparação (planejamento), fase de execução e controle (realização) e fase de autorreflexão (avaliação). Este processo se concretiza de forma dinâmica, aberta e cíclica e, de acordo com Samruayruen et al. (2013), a aprendizagem autorregulada é definida como um comportamento de aprendizagem guiado pela metacognição e autoeficácia (motivação).

A autoeficácia interfere na autorregulação porque está associada à antecipação, seleção e preparação da ação. As crenças de autoeficácia influenciam os padrões de autorregulação que serão adotados pelo indivíduo, o tipo de escolhas diante das decisões necessárias e o nível de esforço a ser investido em determinada meta (BANDURA et al., 2003). E, de forma recíproca, a autorregulação impacta a crença de autoeficácia ao fornecer informações sobre o desempenho, o esforço e o tempo despendido na realização da atividade, participando de sua construção (CLEARY; ZIMMERMAN, 2004). 


\section{FATORES EXPLICATIVOS DO NÍVEL DE UTILIZAÇÃO DAS ESTRATÉGIAS METACOGNITIVAS DE APRENDIZAGEM AUTORREGULADA DOS ESTUDANTES DE CONTABILIDADE \\ DOI: https://doi.org/10.5007/1983-4535.2021.e79844}

Bandura (1982) afirma que as pessoas são influenciadas mais pela forma como percebem suas performances de sucesso, do que pelo sucesso em si. Neste sentido, a síndrome do impostor pode comprometer o objetivo e a meta educacional determinados pelo estudante de contabilidade, uma vez que os impostores julgam que o sucesso é obra do acaso e não resultado da capacidade, bem como a autoconsequência, pois sua definição aborda que o discente adere a autopremiação e/ou autopunição pela ocorrência do sucesso e/ou insucesso de seu desempenho. Hill (2002) argumenta que a falta de habilidade metacognitiva pode dificultar, também, a autoavaliação do desempenho das atividades desenvolvidas.

A Síndrome do Impostor (SI) é introduzida na literatura por meio do estudo de Clance e Imes (1978) com 100 mulheres que, embora apresentassem sucesso acadêmico e profissional, não se consideravam merecedoras de tal sucesso. Conforme o estudo, essas mulheres perceberam, devido à sua personalidade e habilidade social, a criação de uma fachada enganosa de inteligência, já que quando expostas aos resultados positivos das tarefas desenvolvidas, negaram o êxito e temeram a descoberta de inadequação intelectual. Para Parkman (2016), a síndrome do impostor é um fenômeno caracterizado pela incapacidade de internalizar o sucesso e a conquista, incluindo a excelência acadêmica.

Os impostores negam qualquer evidência de suas habilidades, rejeitam qualquer afirmação agradável sobre o seu sucesso e, intimamente, generalizam excessivamente as implicações de um eventual mau desempenho, sendo incapazes de aceitar um retorno positivo (CLANCE, 1986). Assim, por acreditarem que o êxito não é resultado de suas habilidades, eles reforçam as suas crenças mediante dois tipos de comportamentos: 1) excesso de preparo e 2) procrastinador. No primeiro tipo de comportamento, o impostor começa a trabalhar na tarefa imediatamente após recebê-la, despendendo muito mais tempo e trabalho do que o necessário (COWMAN; FERRARI, 2002). Ao executar adequadamente a atividade proposta, aflora a ideia de que o sucesso é fruto de um trabalho pesado e de uma melhor preparação face aos demais concorrentes (CLANCE; IMES, 1978). Nesse sentido, por acharem que não são merecedores do sucesso, criam obstáculos para se preservarem do medo do fracasso (COWMAN; FERRARI, 2002) e atribuem o sucesso ao acaso e aos bons momentos (PARKMAN, 2016). Já no segundo tipo de comportamento, o impostor deixa a tarefa para a última hora, terminando em cima do prazo e, caso haja sucesso, o atribui a sorte (CLANCE; IMES, 1978). 


\section{FATORES EXPLICATIVOS DO NÍVEL DE UTILIZAÇÃO DAS ESTRATÉGIAS METACOGNITIVAS DE APRENDIZAGEM AUTORREGULADA DOS ESTUDANTES DE CONTABILIDADE \\ DOI: https://doi.org/10.5007/1983-4535.2021.e79844}

Com base neste contexto, o estudante de contabilidade pode fazer uso do repertório de estratégias metacognitivas de aprendizagem autorregulada e ser um impostor com excesso de preparo ou procrastinador. No comportamento com excesso de preparo, é provável que o discente tenha um alto grau de utilização das estratégias metacognitivas de aprendizagem, o que pode auxiliá-lo no desenvolvimento da tarefa. Entretanto, no comportamento procrastinador, o estudante pode não usar as estratégias metacognitivas, como as estratégias da fase de planejamento e avaliação por exemplo, uma vez que deixa a tarefa para a última hora.

A síndrome do impostor tem sido explorada na literatura estrangeira (CLANCE; IMES, 1978; COZZARELLI; MAJOR, 1990; HOLMES et al., 1993; HENNING; EY; SHAW, 1998; COWMAN; FERRARI, 2002; CASTRO; JONES; MIRSALIMI, 2004; FERRARI, 2005; PARKMAN, 2016). Em contexto nacional, Matos (2014) investigou a influência do fenômeno impostor e da autoeficácia no desempenho acadêmico dos alunos minoritários, entendidos como estudantes bolsistas, sobretudo do ProUni e Enade, dos cursos de Ciências Contábeis e Administração de Empresas. A amostra foi composta por 492 alunos de quatro instituições de ensino privadas estabelecidas no estado de São Paulo e a correlação de Pearson indicou que a síndrome do impostor apresenta relação negativa com a autoeficácia. Complementarmente, o autor supracitado ressalta que o estudo é embrionário no Brasil e que a literatura brasileira sobre o tema ainda é escassa.

Posto isto, a análise que este estudo pretende alcançar é inédita por buscar relacionar as estratégias metacognitivas de aprendizagem autorregulada, além da síndrome do impostor, com o comportamento dos estudantes de contabilidade. No campo das estratégias metacognitivas, poucos estudos se dedicaram a investigar o tema na educação contábil, segundo Schleifer e Dull (2009), Byrne, Flood e Willis (2009), Becker (2011), Lima Filho, Lima e Bruni (2015), Silva (2016), Silva et al. (2016) e Silva e Biavatti (2018). Estes estudos apenas estabeleceram a associação entre as estratégias metacognitivas e o desempenho acadêmico, identificaram o papel da intervenção e analisaram o nível de desenvolvimento das estratégias metacognitivas ao longo do curso. Assim, diante de tais evidências e ao considerar tal lacuna de investigação, busca-se identificar os fatores que explicam o nível de utilização das estratégias metacognitivas de aprendizagem autorregulada dos estudantes de contabilidade. 


\section{PROCEDIMENTOS METODOLÓGICOS}

Para atingir o objetivo proposto, utiliza-se dados provenientes de questionários aplicados aos discentes do curso presencial de Ciências Contábeis de uma instituição federal do estado do Mato Grosso do Sul/Brasil. A aplicação é realizada no primeiro semestre de 2018 e, no total, 107 estudantes responderam os questionários entregues em formato impresso ou eletrônico via e-mail.

Esse instrumento de coleta de dados é formado por perguntas que caracterizam o respondente, como nome, gênero, idade, estágio no curso, tempo de estudo, perguntas que visam identificar o nível de utilização das estratégias metacognitivas de aprendizagem autorregulada e por perguntas que detectam o grau da síndrome do impostor. Ressalta-se que o nome do estudante é solicitado com o intuito de conseguir a nota de desempenho acadêmico (I.D.A) na secretaria acadêmica por meio do relatório de acadêmicos ativos com I.D.A. Todos os discentes autorizaram o uso do I.D.A para o estudo.

No Quadro 1, apresenta-se o instrumento utilizado para obtenção dos dados concernentes as estratégias metacognitivas de aprendizagem autorregulada. Vale destacar que a seleção deste instrumento se dá a partir da análise de frequência do seu uso na literatura e que os discentes são convidados a fundamentar suas respostas em suas experiências, devendo escolher entre 1 (Nunca) e 5 (Sempre).

Utiliza-se a escala CIPS - Clance Impostor Phenomenon Scale - desenvolvida por Clance (1986) para detectar os sintomas do fenômeno do impostor. Essa escala é composta por 20 itens, que contêm elementos que identificam (a) o medo da avaliação, (b) o medo da incapacidade de repetir o sucesso e (c) o medo de ser menos capaz do que os outros, apresentados no formato likert de cinco pontos, sendo 1 (não é de todo verdade) e 5 (muito verdadeiro). A validação e consistência da escala CIPS têm sido corroboradas por diversas pesquisas (COZZARELLI; MAJOR, 1990; HOLMES et al., 1993; MATOS, 2014; ASHRAFIFARD; MAFAKHERI, 2017).

Os resultados da escala determinam se o estudante possui ou não características da síndrome do impostor. Segundo Clance (1986), se a pontuação é superior a 80 pontos, o discente apresenta nível elevado do fenômeno; pontuações entre 61 e 80 revelam níveis altos do fenômeno do impostor; valores totais entre 41 e 60 representam níveis moderados e valores totais menores que 40 pontos indicam níveis baixos. Exibe-se na Tabela 1 as variáveis da pesquisa. 


\section{FATORES EXPLICATIVOS DO NÍVEL DE UTILIZAÇÃO DAS ESTRATÉGIAS METACOGNITIVAS DE APRENDIZAGEM AUTORREGULADA DOS ESTUDANTES DE CONTABILIDADE \\ DOI: https://doi.org/10.5007/1983-4535.2021.e79844}

Quadro 1 Afirmações e estratégias metacognitivas de aprendizagem autorregulada

\begin{tabular}{|l|l|}
\hline \multicolumn{1}{|c|}{ Afirmações } & \multicolumn{1}{|c|}{ Estratégias } \\
\hline $\begin{array}{l}\text { 1. Avalio o meu desempenho, vejo o que devo } \\
\text { melhorar e procuro superar dificuldades detectadas }\end{array}$ & 1. Autoavaliação \\
\hline $\begin{array}{l}\text { 2. Procuro sempre elaborar um plano (esquema) } \\
\text { antes de iniciar um trabalho }\end{array}$ & 2. Organização e transformação \\
\hline $\begin{array}{l}\text { 3. Se tenho prova, começo a estudar o mais cedo } \\
\text { possível, para ficar descansado e tranquilo no dia }\end{array}$ & 3. Estabelecimento de objetivos e planejamento \\
\hline $\begin{array}{l}\text { 4. Antes de iniciar um trabalho, recorro sempre à } \\
\text { biblioteca (e outros meios de pesquisa seja físico } \\
\text { ou digital) parar separar o máximo de informação } \\
\text { sobre o tema }\end{array}$ & 4. Procura de informação \\
\hline $\begin{array}{l}\text { 5. Sempre procuro anotar o máximo de } \\
\text { apontamentos de um texto lido ou da aula } \\
\text { expositiva do professor }\end{array}$ & 5. Tomada de apontamentos \\
\hline $\begin{array}{l}\text { 6. Para ter melhor concentração, procuro sempre } \\
\text { ambiente que não proporcione distração }\end{array}$ & 6. Estrutura ambiental \\
\hline $\begin{array}{l}\text { 7. Quando faço uma prova, se ocorrer bem, } \\
\text { ofereço-me recompensa; caso ocorra o contrário, } \\
\text { abro mão de algo que tanto queria }\end{array}$ & 7. Autoconsequência \\
\hline $\begin{array}{l}\text { 8. Utilizo estratégias para memorizar o assunto (ou } \\
\text { fórmulas), até saber de cor o assunto a ser estudado }\end{array}$ & 8. Repetição e memorização \\
\hline $\begin{array}{l}\text { 9. Quando surge dificuldade e não consigo resolver } \\
\text { sozinho, busco ajuda externa (professor, colegas, } \\
\text { outros) }\end{array}$ & $\begin{array}{l}\text { 9. Ajuda de professores } \\
\text { 10. Ajuda de pares próximos } \\
\text { 11. Ajuda de especialistas }\end{array}$ \\
\hline $\begin{array}{l}\text { 10. Após conclusão de um trabalho acadêmico, eu } \\
\text { o reviso para ter a certeza de que esteja correto }\end{array}$ & $\begin{array}{l}\text { 12. Revisão das anotações } \\
\text { 13. Revisão de testes } \\
\text { 14. Revisão da bibliografia }\end{array}$ \\
\hline
\end{tabular}

Fonte: Zimmerman e Martinez-Pons (1986) adaptado por Lima Filho, Lima e Bruni (2015).

Fundamentadas em pesquisas anteriores, as variáveis da pesquisa são: dependente nível de utilização das estratégias metacognitivas de aprendizagem autorregulada; e independentes - idade, gênero, estágio no curso, tempo de estudo, nota de desempenho acadêmico e síndrome do impostor.

Os dados são analisados por meio das técnicas de estatística descritiva, análise fatorial e regressão linear múltipla. A identificação das estratégias metacognitivas de aprendizagem autorregulada utilizadas pelos estudantes de contabilidade ocorre com o subsídio da estatística descritiva. Em seguida, calcula-se a análise fatorial com a intenção de resumir e reduzir as informações oriundas das respostas dessas estratégias e, por último, aplicam-se regressões para identificar os fatores que explicam os níveis de utilização das estratégias metacognitivas de aprendizagem autorregulada. 


\section{FATORES EXPLICATIVOS DO NÍVEL DE UTILIZAÇÃO DAS ESTRATÉGIAS METACOGNITIVAS DE APRENDIZAGEM AUTORREGULADA DOS ESTUDANTES DE CONTABILIDADE \\ DOI: https://doi.org/10.5007/1983-4535.2021.e79844}

Tabela 1 Variáveis dependente e independentes da pesquisa

\begin{tabular}{|c|c|c|c|}
\hline $\begin{array}{l}\text { VARIÁVEIS DA } \\
\text { PESQUISA }\end{array}$ & PROXY & FUNDAMENTAÇÃO & COMPORTAMENTO \\
\hline \multicolumn{4}{|c|}{ Variável dependente } \\
\hline $\begin{array}{l}\text { Nível de utilização } \\
\text { das estratégias } \\
\text { metacognitivas de } \\
\text { aprendizagem } \\
\text { autorregulada }\end{array}$ & $\begin{array}{l}\text { Dimensão originária da } \\
\text { análise fatorial }\end{array}$ & $\begin{array}{l}\text { Schleifer e Dull (2009); Byrne, Flood e } \\
\text { Willis (2009); Becker (2011); Becker } \\
\text { (2013); Lima Filho, Lima e Bruni } \\
\text { (2015); Silva et al. (2016); Silva e } \\
\text { Biavatti (2018); Silva et al. (2020) }\end{array}$ & \\
\hline \multicolumn{4}{|c|}{ Variáveis independentes } \\
\hline Idade & $\begin{array}{l}\text { Idade do estudante em } \\
\text { anos }\end{array}$ & $\begin{array}{l}\text { Lima Filho, Lima e Bruni (2015); Pavesi } \\
\text { e Alliprandini (2015); Silva et al. (2016) }\end{array}$ & Positivo \\
\hline Gênero & $\begin{array}{l}\text { Valor 0 (zero) } \\
\text { estudante do } \\
\text { masculino; } \\
\text { Valor } 1 \text { (um) } \\
\text { estudante do } \\
\text { feminino }\end{array}$ & $\begin{array}{l}\text { Bembenutty (2007); Lima Filho, Lima e } \\
\text { Bruni (2015); Pavesi e Alliprandini } \\
\text { (2015); Silva et al. (2016) }\end{array}$ & Positivo \\
\hline Estágio no curso & $\begin{array}{l}\text { Valor } 1 \text { (um) para o } 1^{\circ} \\
\text { semestre; } \\
\text { Valor } 2 \text { (dois) para o } 2^{\circ} \\
\text { semestre; [...] } \\
\text { Valor } 8 \text { (oito) para o } 8^{\circ} \\
\text { semestre }\end{array}$ & $\begin{array}{l}\text { Rosário (2001); Sperling et al. (2004); } \\
\text { Lombaerts, Engels e Van Braak (2009); } \\
\text { Schleifer e Dull (2009); Lima Filho, } \\
\text { Lima e Bruni (2015); Silva et al. (2016) }\end{array}$ & Positivo/negativo \\
\hline Tempo de estudo & 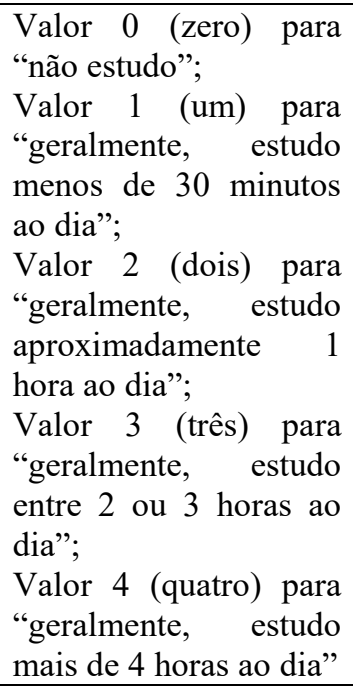 & $\begin{array}{l}\text { Chambers (1992); Ericsson e Charnes } \\
\text { (1994) }\end{array}$ & Positivo \\
\hline $\begin{array}{l}\text { Nota de desempenho } \\
\text { acadêmico (I.D.A) }\end{array}$ & $\begin{array}{l}\text { Escore da nota de } \\
\text { desempenho } \\
\text { acadêmico }\end{array}$ & $\begin{array}{l}\text { Oliveira, Boruchovitch e Santos (2009); } \\
\text { Schleifer e Dull (2009); Parra et al. } \\
\text { (2014) }\end{array}$ & Positivo \\
\hline $\begin{array}{l}\text { Síndrome do } \\
\text { impostor }\end{array}$ & $\begin{array}{lrr}\text { Resultado } & \text { da } \\
\text { pontuação } & \text { da } & \text { escala } \\
\text { CIPS } & & \end{array}$ & $\begin{array}{l}\text { Matos (2014); Ashrafifard e Mafakheri } \\
\text { (2017) }\end{array}$ & Positivo/Negativo \\
\hline
\end{tabular}

Fonte: Dados da pesquisa.

Além disso, verifica-se a intensidade e o sentido das relações entre as variáveis, a partir do cálculo do coeficiente de correlação de Pearson. Aplica-se, também, o teste não paramétrico de Kolmogorov-Smirnov para averiguar a normalidade ou não dos resíduos, que evidencia distribuição normal a um nível de 5\%. 


\section{ANÁLISE E DISCUSSÃO DOS RESULTADOS}

Inicialmente, apresenta-se, na Tabela 2, a caracterização dos estudantes conforme o gênero, idade, estágio no curso, tempo de estudo, nota de desempenho acadêmico e grau da síndrome do impostor.

Tabela 2 Caracterização dos estudantes

\begin{tabular}{|c|c|c|c|c|}
\hline \multirow{2}{*}{\multicolumn{2}{|c|}{$\frac{\text { Amostra }}{\text { Total }}$}} & \multicolumn{3}{|c|}{ Gênero } \\
\hline & & \multirow{2}{*}{\multicolumn{2}{|c|}{$\begin{array}{c}\text { Feminino } \\
\mathrm{Fi}=54 \text { e } \mathrm{Fi} \%=50,47\end{array}$}} & Masculino \\
\hline $\mathrm{Fi}=107$ & $\mathrm{Fi} \%=100$ & & & $\mathrm{Fi}=53$ e $\mathrm{Fi} \%=49,53$ \\
\hline \multicolumn{5}{|c|}{ Idade (anos) } \\
\hline Até 20 & De 21 a 25 & De 26 a 30 & De 31 a 35 & Acima de 35 \\
\hline $42(39,25 \%)$ & $47(43,93 \%)$ & $9(8,41 \%)$ & $5(4,67 \%)$ & $4(3,74 \%)$ \\
\hline \multicolumn{5}{|c|}{ Estágio no curso (semestre) } \\
\hline $2^{\circ}$ & $4^{\circ}$ & $6^{\circ}$ & & $8^{\circ}$ \\
\hline $39(36,45 \%)$ & $25(23,36 \%)$ & $21(19,63$ & & $22(20,56 \%)$ \\
\hline \multicolumn{5}{|c|}{ Tempo de estudo (diário) } \\
\hline não estudo & $\begin{array}{c}\text { menos de } 30 \text { minutos ao } \\
\text { dia }\end{array}$ & $\begin{array}{c}\text { aproximadamente } 1 \\
\text { hora ao dia }\end{array}$ & $\begin{array}{l}\text { entre } 2 \text { ou } 3 \\
\text { horas ao dia }\end{array}$ & $\begin{array}{c}\text { mais de } 4 \text { horas ao } \\
\text { dia }\end{array}$ \\
\hline $20(18,69 \%)$ & $38(35,51 \%)$ & $28(26,17 \%)$ & $18(16,82 \%)$ & $3(2,80 \%)$ \\
\hline \multicolumn{5}{|c|}{ Nota de desempenho acadêmico } \\
\hline Média & Mínimo & Máximo & Des & svio-padrão \\
\hline 6,97 & 2,76 & 8,94 & & 1,23 \\
\hline \multicolumn{5}{|c|}{ Síndrome do impostor } \\
\hline Elevado & Alto & Moder & & Baixo \\
\hline $17(15,89 \%)$ & $32(29,91 \%)$ & $38(35,5$ & & $20(18,69 \%)$ \\
\hline
\end{tabular}

Fonte: Dados da pesquisa.

Ao analisar a Tabela 2, nota-se o equilíbrio entre os gêneros; a predominância da faixa etária de 21 a 25 anos (43,93\%); que a maioria se encontra no segundo semestre (36,45\%); que a média da nota de desempenho acadêmico é de 6,97 com desvio-padrão de 1,23; e que o tempo de estudo diário com maior frequência é menos de 30 minutos/dia $(35,51 \%)$, que $18,69 \%$ não estuda e que apenas 2,80\% estuda mais de 4 horas/dia. Quanto a síndrome do impostor, a maioria (35,51\%) possui grau moderado, $15,89 \%$ grau elevado, $29,91 \%$ grau alto e $18,69 \%$ grau baixo.

$\mathrm{Na}$ Tabela 3, identifica-se as estratégias metacognitivas de aprendizagem autorregulada utilizadas pelos estudantes para o cumprimento de suas atividades acadêmicas. Nas duas últimas colunas têm-se o total das frequências para as respostas menores e maiores que três, sendo este o ponto médio entre 1 e 5. 
Tabela 3 Estatística descritiva das estratégias metacognitivas de aprendizagem autorregulada dos estudantes

\begin{tabular}{|c|c|c|c|c|c|c|c|c|c|}
\hline \multirow{2}{*}{\multicolumn{2}{|c|}{ Estratégia }} & \multicolumn{8}{|c|}{ Respostas } \\
\hline & & \multirow{2}{*}{$\begin{array}{c}1 \\
\text { Nunca } \\
6 \\
5,61 \% \\
\end{array}$} & \multirow{2}{*}{$\begin{array}{c}2 \\
14 \\
13,08 \% \\
\end{array}$} & \multirow{2}{*}{$\begin{array}{c}3 \\
18 \\
16,82 \%\end{array}$} & \multirow{2}{*}{$\begin{array}{c}4 \\
21 \\
19,63 \%\end{array}$} & \multirow{2}{*}{$\begin{array}{c}5 \\
\text { Sempre } \\
48 \\
44,86 \%\end{array}$} & Total & \multirow{2}{*}{\begin{tabular}{|c|} 
Menor que 3 \\
20 \\
$18,69 \%$ \\
\end{tabular}} & \multirow{2}{*}{$\begin{array}{c}\text { Maior que } 3 \\
699 \\
64,49 \% \\
\end{array}$} \\
\hline E1 & Total & & & & & & & & \\
\hline E2 & Total & $\begin{array}{c}26 \\
24,30 \%\end{array}$ & $\begin{array}{c}14 \\
13,08 \%\end{array}$ & $\begin{array}{c}21 \\
19,63 \%\end{array}$ & $\begin{array}{c}11 \\
10,28 \%\end{array}$ & $\begin{array}{c}35 \\
32,71 \%\end{array}$ & & $\begin{array}{c}40 \\
37,38 \%\end{array}$ & $\begin{array}{c}46 \\
42,99 \%\end{array}$ \\
\hline E3 & Total & $\begin{array}{c}26 \\
24,30 \%\end{array}$ & $\begin{array}{c}23 \\
21,50 \%\end{array}$ & $\begin{array}{c}25 \\
23,36 \%\end{array}$ & $\begin{array}{c}15 \\
14,02 \%\end{array}$ & $\begin{array}{c}18 \\
16,82 \%\end{array}$ & & $\begin{array}{c}49 \\
45,79 \%\end{array}$ & $\begin{array}{c}33 \\
30,84 \%\end{array}$ \\
\hline E4 & Total & $\begin{array}{c}25 \\
23,36 \% \\
\end{array}$ & $\begin{array}{c}14 \\
13,08 \% \\
\end{array}$ & $\begin{array}{c}11 \\
10,28 \% \\
\end{array}$ & $\begin{array}{c}17 \\
15,89 \% \\
\end{array}$ & $\begin{array}{c}40 \\
37,38 \% \\
\end{array}$ & & $\begin{array}{c}39 \\
36,45 \% \\
\end{array}$ & $\begin{array}{c}57 \\
53,27 \% \\
\end{array}$ \\
\hline E5 & Total & $\begin{array}{c}9 \\
8,41 \%\end{array}$ & $\begin{array}{c}13 \\
12,15 \%\end{array}$ & $\begin{array}{c}25 \\
23,36 \%\end{array}$ & $\begin{array}{c}13 \\
12,15 \%\end{array}$ & $\begin{array}{c}47 \\
43,93 \%\end{array}$ & & $\begin{array}{c}22 \\
20,56 \%\end{array}$ & $\begin{array}{c}60 \\
56,07 \%\end{array}$ \\
\hline E6 & Total & $\begin{array}{c}13 \\
12,15 \% \\
\end{array}$ & $\begin{array}{c}9 \\
8,41 \% \\
\end{array}$ & $\begin{array}{c}25 \\
23,36 \%\end{array}$ & $\begin{array}{c}15 \\
14,02 \% \\
\end{array}$ & $\begin{array}{c}45 \\
42,06 \%\end{array}$ & 107 & $\begin{array}{c}22 \\
20,56 \%\end{array}$ & $\begin{array}{c}60 \\
56,07 \%\end{array}$ \\
\hline E7 & Total & $\begin{array}{c}66 \\
61,68 \% \\
\end{array}$ & $\begin{array}{c}17 \\
15,89 \% \\
\end{array}$ & $\begin{array}{c}9 \\
8,41 \% \\
\end{array}$ & $\begin{array}{c}14 \\
13,08 \% \\
\end{array}$ & $\begin{array}{c}1 \\
0,93 \% \\
\end{array}$ & & $\begin{array}{c}83 \\
77,57 \% \\
\end{array}$ & $\begin{array}{c}15 \\
14,02 \% \\
\end{array}$ \\
\hline E8 & Total & $\begin{array}{c}24 \\
22,43 \%\end{array}$ & $\begin{array}{c}17 \\
15,89 \%\end{array}$ & $\begin{array}{c}14 \\
13,08 \%\end{array}$ & $\begin{array}{c}23 \\
21,50 \%\end{array}$ & $\begin{array}{c}29 \\
27,10 \%\end{array}$ & & $\begin{array}{c}41 \\
38,32 \%\end{array}$ & $\begin{array}{c}52 \\
48,60 \%\end{array}$ \\
\hline E9 & Total & $\begin{array}{c}9 \\
8,41 \% \\
\end{array}$ & $\begin{array}{c}6 \\
5,61 \% \\
\end{array}$ & $\begin{array}{c}14 \\
13,08 \%\end{array}$ & $\begin{array}{c}22 \\
20,56 \%\end{array}$ & $\begin{array}{c}56 \\
52,34 \%\end{array}$ & & $\begin{array}{c}15 \\
14,02 \%\end{array}$ & $\begin{array}{c}78 \\
72,90 \%\end{array}$ \\
\hline E10 & Total & $\begin{array}{c}6 \\
5,61 \% \\
\end{array}$ & $\begin{array}{c}15 \\
14,02 \% \\
\end{array}$ & $\begin{array}{c}14 \\
13,08 \% \\
\end{array}$ & $\begin{array}{c}20 \\
18,69 \% \\
\end{array}$ & $\begin{array}{c}52 \\
48,60 \% \\
\end{array}$ & & $\begin{array}{c}21 \\
19,63 \% \\
\end{array}$ & $\begin{array}{c}72 \\
67,29 \% \\
\end{array}$ \\
\hline
\end{tabular}

Legenda: E1 - estratégia de autoavaliação; E2 - estratégia de organização e transformação; E3 estratégia de estabelecimento de objetivos e planejamento; E4 - estratégia de procura de informação; E5 - estratégia de tomada de apontamentos; E6 - estratégia de estrutura ambiental; E7 - estratégia autoconsequência; E8 - estratégia de repetição e memorização; E9 - estratégia de procura de ajuda social; E10 - estratégia de revisão de dados.

Fonte: Dados da pesquisa.

Como resultado, verifica-se, respectivamente, a preferência dos estudantes pelas estratégias E9 (ajuda social), E10 (revisão de dados) e E1 (autoavaliação), que estão concentradas entre as fases de execução e autorreflexão. Percebe-se, ainda, que a predominância das estratégias metacognitivas está acima do ponto médio, com exceção da E2 (organização e transformação), E3 (objetivos e planejamento), E7 (autoconsequência) e E8 (repetição e memorização). Estes achados convergem com os estudos de Lima Filho, Lima e Bruni (2016), Silva et al. (2016) e Silva e Biavatti (2018).

De modo geral, os resultados apontam que os estudantes de contabilidade não empregam as estratégias de estabelecimento de objetivos e planejamento e de autoconsequência. Ao considerar que o processo de autorregulação se concretiza de forma aberta e cíclica, o não uso dessas estratégias pode comprometer as demais fases (execução e controle e autorreflexão), conforme Silva e Biavatti (2018). Para Demetriou (2000), a participação ativa exige consciência dos objetivos a serem atingidos, reconhecimento das 


\section{FATORES EXPLICATIVOS DO NÍVEL DE UTILIZAÇÃO DAS ESTRATÉGIAS METACOGNITIVAS DE APRENDIZAGEM AUTORREGULADA DOS ESTUDANTES DE CONTABILIDADE \\ DOI: https://doi.org/10.5007/1983-4535.2021.e79844}

demandas da ação a se alcançar, separação e estabelecimento dos recursos internos e externos para a execução da ação, avaliação do nível de realização e alteração dos procedimentos utilizados se o resultado não for o previsto.

Na Tabela 4, mostra-se as médias de cada fase da autorregulação, estratificadas pela idade, gênero, nota de desempenho acadêmico, estágio no curso, tempo de estudo e síndrome do impostor. As variáveis são segregadas em grupos como considera os estudos anteriores.

Tabela 4 Médias estratificadas de cada fase da autorregulação

\begin{tabular}{l|cccc}
\hline \multicolumn{1}{c|}{ Variáveis } & Grupo & Planejamento & Execução e autocontrole & Autoavaliação \\
\hline \multirow{4}{*}{ Idade } & Até 20 & $3,33(1,53)$ & $3,70(1,31)$ & $3,73(1,33)$ \\
& 21 a 25 & $2,70(1,43)$ & $3,04(1,29)$ & $3,91(1,14)$ \\
& 26 a 30 & $3,66(1,26)$ & $3,70(1,18)$ & $3,88(1,45)$ \\
\multirow{2}{*}{ Gênero } & 31 a 35 & $3,40(1,01)$ & $3,83(0,89)$ & $4,80(0,45)$ \\
& Acima de 36 & $3,50(1,17)$ & $3,75(0,92)$ & $3,00(2,31)$ \\
\hline \multirow{3}{*}{ Nota de desempenho } & Masculino & $2,96(1,57)$ & $3,20(1,16)$ & $3,94(1,22)$ \\
acadêmico & Feminino & $3,17(1,48)$ & $3,53(1,23)$ & $3,75(1,34)$ \\
& Até 6,00 & $2,95(1,45)$ & $3,23(1,26)$ & $3,86(1,06)$ \\
& 6,01 a 7,00 & $2,84(1,46)$ & $3,27(1,33)$ & $3,50(1,37)$ \\
\multirow{2}{*}{ Estágio no curso } & 7,01 a 8,00 & $2,86(1,65)$ & $3,28(1,33)$ & $3,60(1,37)$ \\
& 8,01 a 9,00 & $3,88(1,25)$ & $3,85(1,14)$ & $4,60(0,94)$ \\
\hline \multirow{4}{*}{ Tempo de estudo } & Até o 5 & $3,20(1,54)$ & $3,40(1,36)$ & $3,80(1,35)$ \\
& A partir do 6 & $2,89(1,49)$ & $3,31(1,29)$ & $3,91(1,19)$ \\
\hline \multirow{2}{*}{ Síndrome } & Não estudo & $2,53(1,51)$ & $3,08(1,40)$ & $3,5(1,47)$ \\
impostor & Menos de 30 min & $3,17(1,51)$ & $3,19(1,35)$ & $3,73(1,20)$ \\
& Aprox. 1 hora & $3,25(1,42)$ & $3,61(1,24)$ & $4,03(1,29)$ \\
& Entre 2 ou 3 horas & $3,50(1,38)$ & $3,50(1,08)$ & $4,00(1,24)$ \\
& Mais de 4 horas & $4,33(0,79)$ & $4,33(0,73)$ & $5,00(0,00)$ \\
\hline
\end{tabular}

Legenda: Desvio-padrão entre parênteses.

Fonte: Dados da pesquisa.

$\mathrm{Na}$ fase de execução e autocontrole, os estudantes entre 31 e 35 anos têm as maiores médias do que as demais idades. Já na fase planejamento, os estudantes de 26 a 30 anos têm a maior média em relação as outras idades. Entre os gêneros, no feminino as médias são superiores nas fases de planejamento e execução e controle. Sobre o desempenho acadêmico (I.D.A), as maiores notas também apresentam as maiores médias em todas as fases. Quanto ao estágio no curso, os estudantes que cursam a partir do $6^{\circ}$ semestre obtém médias superiores nas fases de execução e autocontrole e autoavaliação. Acerca de o tempo de estudo, as maiores médias são dos alunos que estudam mais de 4 horas/dia em todas as fases. Por fim, sobre a síndrome do impostor, as maiores médias em todas as fases da autorregulação são dos 


\section{FATORES EXPLICATIVOS DO NÍVEL DE UTILIZAÇÃO DAS ESTRATÉGIAS METACOGNITIVAS DE APRENDIZAGEM AUTORREGULADA DOS ESTUDANTES DE CONTABILIDADE \\ DOI: https://doi.org/10.5007/1983-4535.2021.e79844}

estudantes que possuem grau elevado deste fenômeno. Posto isto, os resultados sugerem que a nota de desempenho acadêmico, o tempo de estudo e a síndrome do impostor podem ter relação com o nível de utilização das estratégias metacognitivas da aprendizagem autorregulada (ASHRAFIFARD; MAFAKHERI, 2017; BOWMAN; PALMER, 2017).

Após identificar as estratégias de aprendizagem autorregulada utilizadas pelos estudantes de contabilidade, a partir da próxima tabela, tem-se a sua análise fatorial por componente principal.

Tabela 5 Análise fatorial por componente principal das estratégias de aprendizagem autorregulada (SRL)

\begin{tabular}{|c|c|c|c|c|c|c|}
\hline \multirow{3}{*}{ Componente } & \multicolumn{3}{|c|}{ Autovalor inicial } & \multicolumn{3}{|c|}{ Somas extraídas dos carregamentos } \\
\hline & \multirow{2}{*}{ Total } & \multirow{2}{*}{ \% da Variância } & \multirow{2}{*}{$\%$ Acumulado } & \multirow{2}{*}{ Total } & \multicolumn{2}{|c|}{ Quadráticos } \\
\hline & & & & & \% da Variância & $\%$ Acumulado \\
\hline 1 & 3,823 & 38,225 & 38,225 & 2,443 & 24,435 & 24,435 \\
\hline 2 & 1,326 & 13,262 & 51,487 & 2,225 & 22,254 & 46,689 \\
\hline 3 & 1,149 & 11,494 & 62,981 & 1,629 & 16,292 & 62,981 \\
\hline 4 & 0,847 & 8,469 & 71,451 & & & \\
\hline 5 & 0,685 & 6,852 & 78,302 & & & \\
\hline 6 & 0,590 & 5,897 & 84,200 & & & \\
\hline 7 & 0,490 & 4,900 & 89,100 & & & \\
\hline 8 & 0,410 & 4,101 & 93,200 & & & \\
\hline 9 & 0,387 & 3,871 & 97,072 & & & \\
\hline 10 & 0,293 & 2,928 & 100,000 & & & \\
\hline
\end{tabular}

Fonte: Dados da pesquisa.

A Tabela 5 mostra o autovalor de cada componente e as somas extraídas dos carregamentos. Dado que três componentes apresentam autovalor maior que 1 (um), três fatores são gerados, com percentual acumulado de informação de $24,43 \%$ para o primeiro fator, $46,69 \%$ para o segundo fator e $62,98 \%$ para o terceiro fator. Destaca-se que os critérios usados na definição do número de fatores são o teste Kaiser, que considera apenas os autovalores superiores a 1, e o percentual acumulado da variância compartilhada maior que 0,60; que o valor do teste KMO $(0,782)$ é considerado desejável; que o teste de Esfericidade de Bartlett apresenta baixo nível de significância $(0,000)$ e que o Alfa de Conbrach $(0,764)$ também é adequado, conforme Menezes (2006) e Hair Jr. et al. (2009).

Utiliza-se o método de rotação oblíqua Promax para analisar os coeficientes de correlação, visto que a Promax disponibiliza duas matrizes, uma padrão e uma de estrutura, além da matriz fatorial, para delinear os padrões de correlação entre as variáveis (CATTELL, 1966). Assim, as cargas fatoriais determinam os padrões e o grau de envolvimento de cada variável com os padrões; a matriz padrão, Pattern Matrix, demonstra quais variáveis estão 


\section{FATORES EXPLICATIVOS DO NÍVEL DE UTILIZAÇÃO DAS ESTRATÉGIAS METACOGNITIVAS DE APRENDIZAGEM AUTORREGULADA DOS ESTUDANTES DE CONTABILIDADE \\ DOI: https://doi.org/10.5007/1983-4535.2021.e79844}

altamente envolvidas pelas cargas fatoriais em cada padrão ou cluster; e a matriz de estrutura informa à extensão da correlação das variáveis com os padrões de forma geral. A Tabela 6 relata os coeficientes de correlação com rotação oblíqua Promax.

Tabela 6 Coeficientes de correlação com rotação oblíqua Promax

\begin{tabular}{ccccccccccc}
\hline Dimensão & E1 & E2 & E3 & E4 & E5 & E6 & E7 & E8 & E9 & E10 \\
\hline 1 & & & 0,413 & 0,609 & 0,491 & & & & 0,793 & 0,822 \\
2 & 0,845 & 0,526 & & & & 0,759 & & & & \\
3 & & & & & & & 0,866 & 0,610 & & \\
\hline
\end{tabular}

Legenda: E1 - estratégia de autoavaliação; E2 - estratégia de organização e transformação; E3 estratégia de estabelecimento de objetivos e planejamento; E4 - estratégia de procura de informação; E5 - estratégia de tomada de apontamentos; E6 - estratégia de estrutura ambiental; E7 - estratégia autoconsequência; E8 - estratégia de repetição e memorização; E9 - estratégia de procura de ajuda social; E10 - estratégia de revisão de dados.

Fonte: Dados da pesquisa.

Nota-se na Tabela 6 três dimensões: a primeira formada por E3 (estabelecimento de objetivos e planejamento), E4 (procura de informação), E5 (tomada de apontamentos), E9 (ajuda social) e E10 (revisões); a segunda formada por E1 (autoavaliação), E2 (organização e transformação) e E6 (estrutura ambiental); e a terceira dimensão formada por E7 (autoconsequência) e E8 (repetição e memorização). Como as dimensões são nomeadas conforme o nome e a fase de cada estratégia, a primeira é Estabelecimento de objetivos e Execução SRL, a segunda é Autoavaliação, Organização e Estrutura Ambiental SRL e a terceira é Autoconsequência e Repetição e memória SRL.

Em seguida, busca-se identificar os fatores explicativos do nível de utilização das estratégias metacognitivas de aprendizagem autorregulada dos estudantes de contabilidade. Vale ressaltar que cada dimensão forma uma variável dependente, por isso três modelos de regressão são estimados, conforme as Tabelas 7, 8 e 9.

Tabela 7 Regressão linear múltipla da dimensão estabelecimento de objetivos e execução SRL

\begin{tabular}{|c|c|c|c|c|c|}
\hline \multirow{2}{*}{ Modelo } & \multicolumn{2}{|c|}{ Coeficientes não padronizados } & \multirow{2}{*}{$\begin{array}{c}\text { Coeficientes } \\
\text { padronizados }\end{array}$} & \multirow{2}{*}{$\mathbf{T}$} & \multirow{2}{*}{ Sig. } \\
\hline & Beta & Modelo padrão & & & \\
\hline (Constante) & $-1,136$ & 0,389 & & $-2,925$ & 0,004 \\
\hline Idade & 0,047 & 0,055 & 0,047 & 0,853 & 0,394 \\
\hline Gênero & 0,177 & 0,112 & 0,089 & 1,582 & 0,115 \\
\hline Desempenho Acadêmico & 0,160 & 0,048 & 0,196 & 3,333 & $0,001 *$ \\
\hline Estágio no curso & $-0,037$ & 0,023 & $-0,089$ & $-1,585$ & 0,114 \\
\hline Tempo de estudo & 0,101 & 0,056 & 0,108 & 1,793 & $0,074 *$ \\
\hline Síndrome do impostor & $-0,001$ & 0,003 & $-0,029$ & $-0,537$ & 0,592 \\
\hline $\mathrm{R}$ & \multicolumn{2}{|c|}{0,313} & Sig $(F)$ & \multicolumn{2}{|c|}{0,000} \\
\hline $\mathrm{R}^{2}$ & \multicolumn{2}{|c|}{0,098} & Durbin-Watson & \multicolumn{2}{|c|}{2,023} \\
\hline
\end{tabular}

Fonte: Dados da pesquisa. 
A Tabela 7 descreve os fatores explicativos do nível de utilização das estratégias que formam a dimensão Estabelecimento de objetivos e Execução. $\mathrm{O} \mathrm{R}^{2}$ apresenta baixo valor relativo, o que permite dizer que as variáveis independentes explicam apenas $9,80 \%$ do nível de utilização das estratégias representadas por esta dimensão.

Sobre as variáveis desempenho acadêmico e tempo de estudo, observa-se significância estatística ao nível de $1 \%$ e de $10 \%$, respectivamente, e, portanto, infere-se que elas influenciam o nível de utilização das estratégias que formam a dimensão Estabelecimento de objetivos e Execução. Neste sentido, acredita-se que os estudantes de contabilidade tendem a planejar, executar e concluir suas atividades educacionais com base nos seus objetivos (ZIMMERMAN, 2000). Este resultado vai ao encontro dos estudos de Sperling et al. (2004) e Schleifer e Dull (2009), visto que o desempenho acadêmico e o tempo de estudo também possuem relação significativa e positiva com o nível de utilização das estratégias de aprendizagem. Para Schleifer e Dull (2009), se os discentes gastam mais tempo estudando, eles demandam maior nível de uso das estratégias metacognitivas. As demais variáveis não apresentam significância.

Na Tabela 8, exibem-se os fatores que explicam o nível de utilização das estratégias que formam a dimensão Autoavaliação, Organização e Estrutura Ambiental.

Tabela 8 Regressão linear múltipla da dimensão autoavaliação, organização e estrutura ambiental SRL

\begin{tabular}{|c|c|c|c|c|c|}
\hline \multirow{2}{*}{ Modelo } & \multicolumn{2}{|c|}{ Coeficientes não padronizados } & \multirow{2}{*}{$\begin{array}{c}\text { Coeficientes } \\
\text { padronizados } \\
\text { Beta }\end{array}$} & \multirow{2}{*}{$\mathbf{T}$} & \multirow{2}{*}{ Sig. } \\
\hline & Beta & Modelo padrão & & & \\
\hline (Constante) & 0,381 & 0,397 & & 0,958 & 0,000 \\
\hline Idade & $-0,029$ & 0,056 & $-0,029$ & $-0,513$ & 0,608 \\
\hline Gênero & $-0,049$ & 0,114 & $-0,024$ & $-0,424$ & 0,672 \\
\hline Desempenho Acadêmico & 0,021 & 0,049 & 0,026 & 0,434 & 0,665 \\
\hline Estágio no curso & 0,017 & 0,024 & 0,041 & 0,716 & 0,474 \\
\hline Tempo de estudo & 0,210 & 0,058 & 0,224 & 3,634 & $0,000^{*}$ \\
\hline Síndrome do impostor & $-0,002$ & 0,003 & $-0,036$ & $-0,655$ & 0,513 \\
\hline $\mathrm{R}$ & \multicolumn{2}{|c|}{0,240} & Sig $(F)$ & \multicolumn{2}{|c|}{0,040} \\
\hline $\mathrm{R}^{2}$ & \multicolumn{2}{|c|}{0,058} & Durbin-Watson & \multicolumn{2}{|c|}{2,060} \\
\hline
\end{tabular}

Fonte: Dados da pesquisa.

O $\mathrm{R}^{2}$ apresenta baixo valor relativo, o que permite dizer que as variáveis independentes explicam apenas 5,80\% do nível de utilização das estratégias representadas por esta segunda dimensão. Nota-se pela Tabela 8 que somente a variável independente tempo de estudo apresenta significância estatística ao nível de 1\% com a variável dependente. Neste interim, quanto maior o tempo de estudo do aluno de contabilidade, maior o uso das 


\section{FATORES EXPLICATIVOS DO NÍVEL DE UTILIZAÇÃO DAS ESTRATÉGIAS METACOGNITIVAS DE APRENDIZAGEM AUTORREGULADA DOS ESTUDANTES DE CONTABILIDADE \\ DOI: https://doi.org/10.5007/1983-4535.2021.e79844}

estratégias que formam a dimensão Autoavaliação, Organização e Estrutura Ambiental, que englobam os processos de autojulgamento e autorreação, que possuem iniciativas de reorganização e que indicam esforços para se ter um ambiente sem distração. De acordo com Ericsson e Charnes (1994), os discentes mais proficientes no uso das estratégias gastam um longo tempo de estudo em trabalho individual, aquilo que chamam de "prática deliberada".

$\mathrm{Na}$ Tabela 9, apresentam-se os resultados sobre os fatores que explicam o nível de utilização das estratégias que formam a dimensão Autoconsequência e Repetição e memória.

Tabela 9 Regressão linear múltipla da dimensão autoconsequência e repetição e memória SRL

\begin{tabular}{c|c|c|c|c|c}
\hline \multirow{2}{*}{ Modelo } & \multicolumn{2}{|c|}{ Coeficientes não padronizados } & $\begin{array}{c}\text { Coeficientes } \\
\text { padronizados }\end{array}$ & \multirow{2}{*}{ T } & Sig. \\
\cline { 2 - 5 } & Beta & Modelo padrão & Beta & & \\
\hline (Constante) & $-1,173$ & 0,392 & & $-2,991$ & 0,003 \\
Idade & 0,148 & 0,055 & 0,148 & 2,668 & $0,008^{*}$ \\
Gênero & $-0,032$ & 0,113 & $-0,016$ & $-0,281$ & 0,779 \\
Desempenho Acadêmico & 0,070 & 0,048 & 0,086 & 1,451 & 0,148 \\
Estágio no curso & $-0,038$ & 0,024 & $-0,090$ & $-1,591$ & 0,113 \\
Tempo de estudo & 0,094 & 0,057 & 0,101 & 1,656 & $0,099^{*}$ \\
Síndrome do impostor & 0,010 & 0,006 & 0,198 & 3,596 & 0,000 \\
\hline $\mathrm{R}$ & \multicolumn{3}{|c|}{0,280} & Sig (F) & \multicolumn{2}{c}{0,000} \\
\hline $\mathrm{R}^{2}$ & 0,081 & Durbin-Watson & \multicolumn{2}{c}{1,745} \\
\hline
\end{tabular}

Fonte: Dados da pesquisa.

Constata-se que o coeficiente de determinação $\left(R^{2}\right)$ para esta terceira dimensão possui valor relativamente baixo, ou seja, que a variação das variáveis independentes explica somente $8,10 \%$ da variação da variável dependente. Como a síndrome do impostor e a idade apresentam relação positiva e estatisticamente significativa ao nível de $1 \%$, pode-se inferir que essas duas variáveis influenciam positivamente o nível de utilização das estratégias que formam a dimensão Autoconsequência e Repetição e memória. Os estudantes de contabilidade que se apropriam dessas estratégias aderem a autopremiação e/ou a autopunição pela ocorrência de sucesso e/ou insucesso no desempenho e se esforçam para memorizar o material.

A relação encontrada entre a síndrome do impostor e o nível de utilização das estratégias metacognitivas de aprendizagem autorregulada converge com as afirmações de Ashrafifard e Mafakheri (2017), uma vez que se encontra uma forma pela qual o fenômeno pode se manifestar. Em linhas gerais, entende-se com esta relação que os estudantes se ancoram na repetição e memorização para dar conta de suas demandas acadêmicas e, de 


\section{FATORES EXPLICATIVOS DO NÍVEL DE UTILIZAÇÃO DAS ESTRATÉGIAS METACOGNITIVAS DE \\ APRENDIZAGEM AUTORREGULADA DOS ESTUDANTES DE CONTABILIDADE \\ DOI: https://doi.org/10.5007/1983-4535.2021.e79844}

acordo com o desempenho, autopremiam-se ou autopunem-se, quando, sobretudo, sentem medo de não serem capazes de repetir o sucesso alcançado anteriormente.

\section{CONSIDERAÇÕES FINAIS}

Para identificar os fatores explicativos do nível de utilização das estratégias metacognitivas de aprendizagem autorregulada, realiza-se uma investigação com 107 estudantes de contabilidade de uma instituição federal do estado do Mato Grosso do Sul/Brasil. Adota-se como instrumento de coleta de dados um questionário, formado por perguntas que visam a caracterização do respondente a partir dos itens de detecção do fenômeno impostor sugeridos por Clance (1986) e das estratégias de aprendizagem definidas por Zimmerman e Martinez-Pons (1986).

A análise ocorre em três etapas. Primeiro, identifica-se o nível de utilização das estratégias por meio da estatística descritiva. Em seguida, aplica-se a análise fatorial com o propósito de resumir e reduzir em dimensões as respostas das estratégias de aprendizagem. Por último, estimam-se as regressões para identificar os fatores que explicam o nível de utilização das estratégias metacognitivas de aprendizagem autorregulada.

As implicações desta investigação promovem referências teóricas adequadas e atualizadas, ao envolver o tempo de estudo, o desempenho acadêmico, a síndrome do impostor e outros fatores no contexto do nível de utilização das estratégias metacognitivas de aprendizagem autorregulada dos estudantes de contabilidade, que proporcionam avanço literário e acadêmico relevante à área.

Já em relação à prática, as descobertas empíricas podem subsidiar professores, pesquisadores, instituições educacionais e programas de pós-graduação a compreenderem como os estudantes de contabilidade estruturam suas ações de planejamento em sala de aula, especialmente porque muitas dessas ações podem estar ancoradas nas próprias referências e atitudes docentes.

Logo, conclui-se que os professores também podem auxiliar o aluno a encontrar o próprio caminho de regulação das atividades que realiza, a valorizar as estratégias que ele utiliza e a descobrir novas trajetórias, conforme recomendações promovidas pelas autoridades de educação e órgãos profissionais de contabilidade, como a Comissão para Mudanças na Educação Contábil (Accounting Education Change Commission - AECC, 1990) e a Associação Americana de Contabilidade (American Accounting Association - AAA) (AECC, 
1990; BEHN et al. 2012), que apontam para a necessidade de uma formação que conduza os estudantes de Contabilidade a adquirirem atributos e habilidades de aprendizagem permanente, ou seja, o desenvolvimento de habilidades metacognitivas.

As limitações servem como oportunidades para novos estudos, pois a amostra limitase a um público específico, os estudantes de uma universidade federal pública do Sul-matogrossense. Seria interessante observar se os resultados são análogos em outros cursos e outras instituições.

\section{REFERÊNCIAS}

ACCOUNTING EDUCATION CHANGE COMMISSION (AECC). Objectives of education for accountants: Position statement number one. Issues in Accounting Education, p. 307$312,1990$.

BEHN, B. K.; EZZELL, W. F.; MURPHY, L. A.; RAYBURN, J. D.; STITH, M. T.; STRAWSER, J. R. The Pathways Commission on Accounting Higher Education: Charting a national strategy for the next generation of accountants. Issues in Accounting Education, v. 27, n. 3, p. 595-600, 2012.

AMERICAN INSTITUTE OF CERTIFIED PUBLIC ACCOUNTANTS (AICPA). The AICPA core competency framework for entry into the accounting profession, New York, 1999.

ASHRAFIFARD, S.; MAFAKHERI, A. Investigating the relationship between attribution styles and metacognitive skills with fear of success among students. Iranian Journal of Psychiatry and Behavioral Sciences, v. 11, n. 2, e9461, 2017.

BANDURA, A. Self-efficacy mechanism in human agency. American Psychologist, v. 37, n. 2, p. 122, 1982.

BANDURA, A. CAPRARA, G. V.; BARBARANELLI, C.; GERBINO, M.; PASTORELLI, C. Role of affective self-regulatory efficacy in diverse spheres of psychosocial functioning. Child Development, v. 74, n. 3, p. 769-782, 2003.

BEMBENUTTY, H. Self-regulation of learning and academic delay of gratification: Gender and ethnic differences among college students. Journal of Advanced Academics, v. 18, n. 4, p. 586-616, 2007.

BECKER, L. L. Self-Regulated Learning in an Introductory Undergraduate Accounting Course. Tese (Doutorado em Educação em Liderança), 179 f., Universidade Estadual do Leste de Tennessee, EUA, 2011.

BECKER, L. L. Self-regulated learning interventions in the introductory accounting course: An empirical study. Issues in Accounting Education, v. 28, n. 3, p. 435-460, 2013. 
BYRNE, M.; FLOOD, B.; WILLIS, P. An Inter-Institutional Exploration of the Learning Approaches of Students Studying Accounting. International Journal of Teaching and Learning in Higher Education, v. 20, n. 2, p. 155-167, 2009.

BOWMAN, L.; PALMER, G. A. Confronting the "Imposter Syndrome" in the Adult Learning Classroom. Adult Education Research Conference. Conference Proceedings, Norman, OK, 2017.

CASTRO, D. M.; JONES, R. A.; MIRSALIMI, H. Parentification and the impostor phenomenon: An empirical investigation. The American Journal of Family Therapy, v. 32, n. 3, p. 205-216, 2004.

CATTELL, R. B. The scree test for the number of factors. Multivariate Behavioral Research, v. 1, n. 2, p. 245-276, 1966.

CHAMBERS, E. Work-load and the quality of student learning. Studies in Higher Education, v. 17, n. 2, p. 141-153, 1992.

CIHANOGLU, M. O. Metacognitive awareness of teacher candidates. Procedia-Social and Behavioral Sciences, v. 46, p. 4529-4533, 2012.

CLANCE, P. R.; IMES, S. A. The imposter phenomenon in high achieving women: Dynamics and therapeutic intervention. Psychotherapy: Theory, Research \& Practice, v. 15, n. 3, p. 241, 1978.

CLANCE, P. R. The impostor phenomenon: When success makes you feel like a fake. Bantam Books, 1986.

CLEARY, T. J.; ZIMMERMAN, B. J. Self-regulation empowerment program: A school-based program to enhance self-regulated and self-motivated cycles of student learning. Psychology in the Schools, v. 41, n. 5, p. 537-550, 2004.

COWMAN, S. E.; FERRARI, J. R. “Am I for real?” Predicting impostor tendencies from self-handicapping and affective components. Social Behavior and Personality: an International Journal, v. 30, n. 2, p. 119-125, 2002.

COZZARELLI, C.; MAJOR, B. Exploring the validity of the impostor phenomenon. Journal of Social and Clinical Psychology, v. 9, n. 4, p. 401-417, 1990.

DEMETRIOU, A. Organization and development of self-understanding and self-regulation: Toward a general theory. In: Handbook of Self-Regulation. Academic Press, p. 209-251, 2000 .

DWECK, C. S. Beliefs that make smart people dumb. Why Smart People Can Be So Stupid, v. 24, p. 41, 2002.

ERICSSON, K. A.; CHARNES, N. Expert performance: Its structure and acquisition. American Psychologist, v. 49, n. 8, p. 725, 1994. 
FLAVELL, J. H. Speculations about the nature and development of metacognition. Metacognition, Motivation and Understanding, p. 21-29, 1987.

FERRARI, J. R. Impostor tendencies and academic dishonesty: Do they cheat their way to success? Social Behavior and Personality, v. 33, n. 1, p. 11-17, 2005.

HAIR JR., J. F.; BLACK, W. C.; BABIN, B. J.; ANDERSON, R. E.; TATHAM, R. L. Análise Multivariada de Dados. (6th ed.). Porto Alegre: Bookman, 2009.

HENNING, K.; EY, S.; SHAW, D. Perfectionism, the impostor phenomenon and psychological adjustment in medical, dental, nursing and pharmacy students. Medical Education, v. 32, n. 5, p. 456-464, 1998.

HILL, R. P. Managing across generations in the 21st century: Important lessons from the ivory trenches. Journal of Management Inquiry, v. 11, n. 1, p. 60-66, 2002.

HOLMES, S. W.; KERTAY, L.; ADAMSON, L. B.; HOLLAND, C. L.; CLANCE, P. R. Measuring the impostor phenomenon: A comparison of Clance's IP Scale and Harvey's IP Scale. Journal of Personality Assessment, v. 60, n. 1, p. 48-59, 1993.

KNOWLES, M. S. Andragogy in Action. San Francisco: Jossey-Bass, 1984.

LIMA FILHO, R. N.; LIMA, G. A. S. F.; BRUNI, A. L. Aprendizagem autorregulada em Contabilidade: diagnósticos, dimensões e explicações. Brazilian Business Review, v. 12, n. 1, p. 38, 2015.

LOMBAERTS, K.; ENGELS, N.; VAN BRAAK, J. Determinants of teachers' recognitions of self-regulated learning practices in elementary education. The Journal of Educational Research, v. 102, n. 3, p. 163-174, 2009.

MATOS, P. A. V. C. Síndrome do impostor e auto-eficácia de minorias sociais: alunos de contabilidade e administração. Dissertação (Mestrado em Contabilidade), Universidade de São Paulo, São Paulo, 2014.

MCCANN, E. J. The Assessment and Importance of Volitional Control in Academic Performance. Doctoral dissertation, University of Texas, Austin, 2000.

MENEZES, I. G. Escalas de Intenções Comportamentais de Comprometimento Organizacional (EICCO): concepção, desenvolvimento, validação e padronização. Dissertação (Mestrado em Psicologia), Universidade Federal da Bahia, Salvador, 2006.

PAPAZOGLOU, E. M. Development of the teacher as metacognitive agent. Doctoral dissertation, Franklin Pierce University, New Hampshire, 2010. 
PARRA, J.; CERDA, C.; LÓPEZ-VARGAS, O.; SAIZ, J. L. Género, autodirección del aprendizaje y desempeño académico en estudiantes de pedagogía. Educación y Educadores, v. 17, n. 1, p. 91-107, 2014.

PARKMAN, A. The imposter phenomenon in higher education: Incidence and impact. Journal of Higher Education Theory and Practice, v. 16, n. 1, p. 51, 2016.

PAVESI, M. A.; ALLIPRANDINI, P. M. Z. Autorregulação da Aprendizagem de Alunos de Cursos a Distância em Função do Sexo. Revista de Ensino, Educação e Ciências Humanas, v. 16, n. 2, p. 100-108, 2015.

PINTRICH, P. R. The role of goal orientation in self-regulated learning. In: Handbook of Self-Regulation. Academic Press, p. 451-502, 2000.

OLIVEIRA, K. L. D.; BORUCHOVITCH, E.; SANTOS, A. A. A. D. Estratégias de aprendizagem e desempenho acadêmico: evidências de validade. Psicologia: Teoria e Pesquisa, v. 25, n. 4, p. 531-536, 2009.

ROSÁRIO, P. Diferenças processuais na aprendizagem: avaliação alternativa das estratégias de auto-regulação da aprendizagem. Psicologia, Educação e Cultura, v. 5, n. 1, p. 87-102, 2001 .

ROSKOWSKI, J. C. R. Imposter phenomenon and counseling self-efficacy: The impact of imposter feelings. Tese de Doutorado. Ball State University, Muncie, 2010.

SAMRUAYRUEN, B.; ENRIQUEZ, J.; NATAKUATOONG, O.; SAMRUAYRUEN, K. Self-regulated learning: A key of a successful learner in online learning environments in Thailand. Journal of Educational Computing Research, v. 48, n. 1, p. 45-69, 2013.

SCHLEIFER, L. L.; DULL, R. B. Metacognition and performance in the accounting classroom. Issues in Accounting Education, v. 24, n. 3, p. 339-367, 2009.

SILVA, T. B. J. Estratégias Metacognitivas de Aprendizagem Autorregulada, Percepção Docente Sobre a Aprendizagem e Métodos Educacionais Em Contabilidade. Dissertação (Mestrado em Ciências Contábeis), Universidade Regional de Blumenau, Santa Catarina, 2016.

SILVA, T. B. J.; BIAVATTI, V. T. Estratégia metacognitiva de aprendizagem autorregulada, percepção docente sobre a aprendizagem e métodos educacionais em contabilidade. Revista Contemporânea de Contabilidade, v. 15, n. 37, p. 3-33, 2018.

SILVA, T. B. J.; FREITAS, M. M.; SALLABERRY, J. D.; FLACH, L. As características dos discentes de Ciências Contábeis e as estratégias metacognitivas de aprendizagem autorregulada. Revista de Gestão e Avaliação Educacional, v. 9, n. 18, p. 1-17, 2020.

SILVA, T. B. J.; HAAG, S.; BIAVATTI, V. T.; LAY, L. A. Estratégias de aprendizagem autorregulada em contabilidade: um estudo em duas instituições privadas do ensino superior catarinense. Revista Mineira de Contabilidade, v. 17, n. 3, p. 5-15, 2016. 
SMITH, P. A. Understanding self-regulated learning and its implications for accounting educators and researchers. Issues in Accounting Education, v. 16, n. 4, p. 663-700, 2001.

STUDENSKA, A. Educational level, gender and foreign language learning self-regulation difficulty. Procedia-Social and Behavioral Sciences, v. 29, p. 1349-1358, 2011.

SPERLING, R. A.; HOWARD, B. C.; STALEY, R.; DUBOIS, N. Metacognition and selfregulated learning constructs. Educational Research and Evaluation, v. 10, n. 2, p. 117-139, 2004.

ZIMMERMAN, B. J., \& MARTINEZ-PONS, M. Development of a structured interview for assessing student use of self-regulated learning strategies. American Educational Research Journal, v. 23, n. 4, p. 614-628, 1986.

ZIMMERMAN, B. J. Attaining self-regulation: A social cognitive perspective. In: Handbook of Self-Regulation. Academic Press, p. 13-39, 2000. 